\title{
MUTAÇÃO DA PAISAGEM URBANA. UM CASO SIGNIFICATIVO NA CIDADE DE SÃO PAULO
}

\author{
a Avenida São Luiz
}

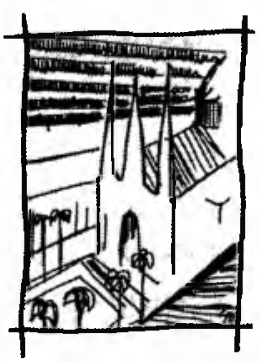

PAULA DA CRUZ LANDIM Y GOYA

Como resultado de pesquisa desenvolvida para bolsa de Iniciação $\mathrm{Ci}$ entífica e também como resultado de Trabalho de Graduação Interdisciplinar "Mutação da Paisagem Urbana: Um Caso Significativo na Cidade de SãoPaulo:a Avenida SãoLuiz"; quese refere fundamentalmenteà formação, transformaçãoe mutaçãodos espaços da referida avenida, desde sua abertura em 1828, então meramente como um caminho, ligando o nascente bairro da Consolação ao que viria ser, muito mais tarde, a Vila Buarque; até os dias de hoje, quando se configura como uma das principais artérias da área central da cidade de São Paulo.

O trabalho buscou detectar e mostrar, flagrantes de diversos períodos, de modo a apresentar uma visão de conjunto nas suas etapas significativas, chegando o mais próximo possível de uma reconstituição das diversas paisagens resultantes.

O processo de reconstituição gráfica foi limitado a dois períodos base: a década de 30/ 40, na qual sabia-se que a avenida mantinha intacto seu aspecto como conjunto urbano significativo do período do ecletismo em São Paulo, e a década de 50, onde já apresentavam-se sinais de mutação, com o desaparecimento de alguns palacetes e a mudança de uso de outros, assim como o início da construção de alguns edifícios.

Éentretanto impossível a reconstituiçãode umapaisagem, principalmente urbana,com absoluta precisão, visto que ela variaconstantemente. Mesmoque fossem mantidas suas edificações primitivas, os jardins se alteram, vias são alargadas, os espaços livres se modificam. Mas namente, na lembrança das pessoas, sobrevivem imagens, sínteses de elementos significativos de uma paisagem de seu cotidiano, e que se encontram vestígios por vezes diluídos nas novas paisagens.

Assim, a avenida São Luiz, apesar de sua dimensão de rua ou de avenida - enquanto morfologia e configuração física - apresenta-secomo um setor urbano muito particular, um enclave na cidade de São Paulo. Uma porção urbana especial, que reflete no seu interior todo o processo de formação da cidade: de área periférica a bairro elegante, de vizinhanças da área central a parte do centro de uma das maiores metrópoles do mundo. 


\section{$1828-1860$}

A cidade de São Paulo, na primeira metade do séc. XIX, era extremamente modesta. Apresentava-se apenas como uma espécie de entreposto comercial entre o porto de Santos e a zona agrícola do interior, onde o café prosperava. O acontecimento mais importante para sua vida de então, foi a instalação da "Academia de Direito", em 1828. Em 1810, a parte dita "urbana" se restinguia à área inicial de sua fundação, com suas funções principais concentradas num triângulo em cujos vértices estavam os conventos de São Francisco, São Bento e Carmo, ou seja, o "Triângulo Central”. Esta "porção" era circundada por um cinturão de chácaras, com importante função residencial, visto que muitas famílias da aristocracia paulistana residiam em suas chácaras; como a do Brigadeiro Luiz Antonio, cuja propriedade, por volta de 1860, ocupava a área compreendida entre as ruas Consolação, Epitácio Pessoa (depois avenida Ipiranga), Sete de Abril, e se prolongava até onde depois existiu o famoso Cine Odeon, na rua da Consolação.

Sua sede, do início do séc. XIX, uma grande casa colonial, ficava onde hoje está a biblioteca municipal Mário de Andrade. Muitas das árvores ainda existentes na praça Dom José Gaspar, faziam parte do pomar da chácara.

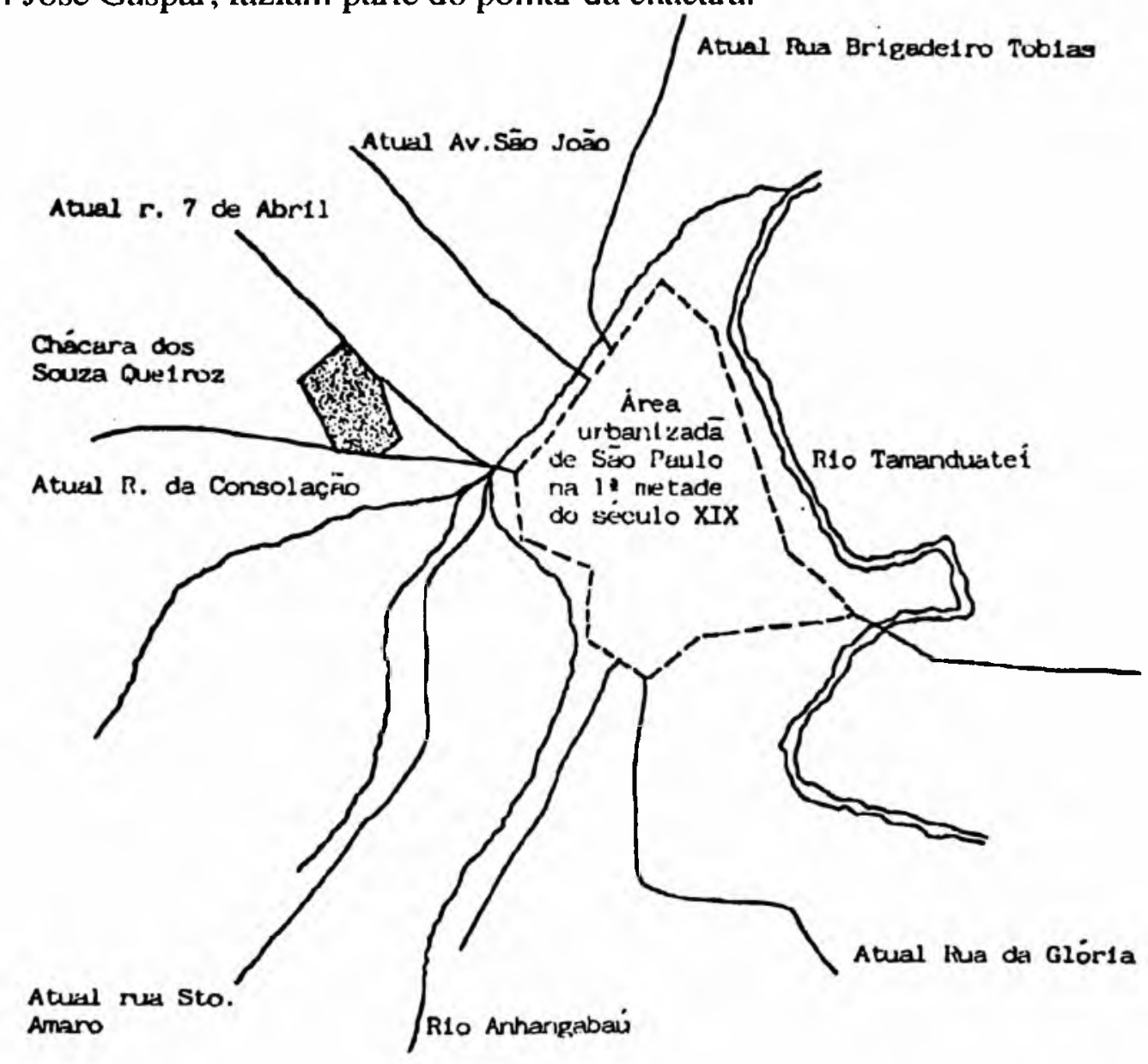


A residência efetiva da família ficava na rua do Ouvidor (hoje José Bonifácio), esquina com a rua São Bento. Tarde da noite, muitas vezes os coches saíam da antiga rua do Ouvidor para a longa caminhada queconduzia à distantechácara da rua da Consolação, a qual só se chegava depois de muitas voltas, pois ainda não existia o viaduto do Chá. Por volta de 1828 , o Brigadeiro mandou abrir uma viela atravessando suas terras. Essa pequena viela facilitou os moradores da região, que antes tinham que contornar toda a propriedade para irem buscar água no antigo Tanque do Arouche, onde hoje está o largo de mesmo nome, na então chácara do Marechal Arouche. Ficou conhecido como Beco Comprido ou rua Comprida, e ligava o bairro da Consolação à futura Vila Buarque.

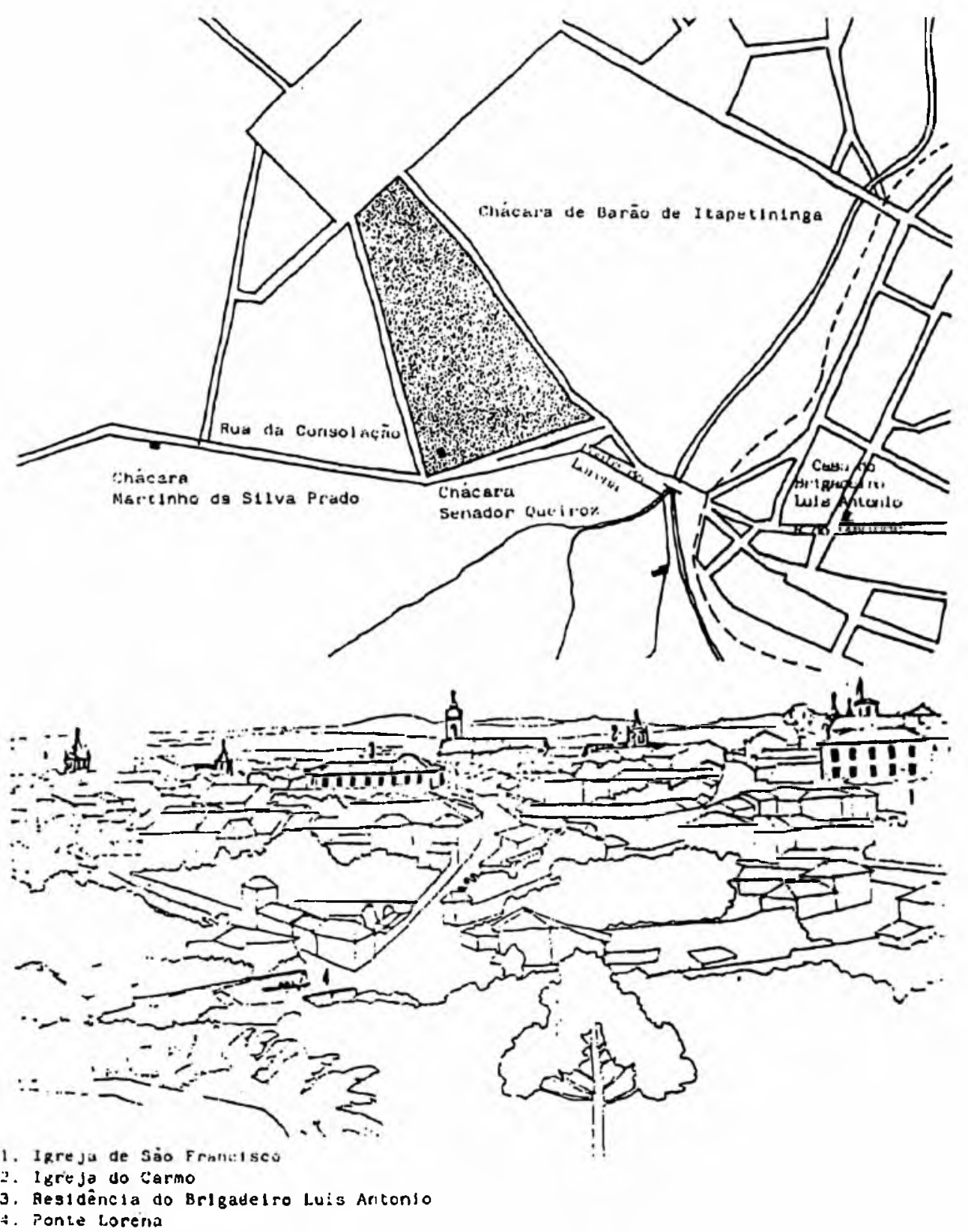




\section{0}

Já na segunda metade do século, a partir de 1870 aproximadamente, São Paulo passa por profundas transformações, com as quais começa a delinear-se a grande metrópole de nossos dias. Se até 1870 continuou a ser um "burgo de estudantes", ou uma "cidade acadêmica" girando em torno da Faculdade de Direito, a partir desta data começa a expandir-se de maneira sempre crescente e imprevisível. A ampliação desta reduzida área urbana processou-se através do retalhamento das chácaras próximas.

Com o café, a cidade passa a atrair quantidades consideráveis de imigrantes europeus, principalmente italianos, que contribuíram de forma decisiva para seu crescimento e expansão.

Com a morte do Brigadeiro, seu filho, o Senador Francisco Antonio de Souza Queiróz, o Barão de Souza Queiróz, alargou o Beco Comprido, arborizou-o com duas fileiras de jacarandás-mimosos, e deu-lhe o nome de rua de São Luiz. "Eram 18 jacarandás apenas, árvores que sombrearam um dia a carruagem de Dom Pedro II, quando o Imperador chegava para recepções na antiga chácara do Brigadeiro Luiz Antonio de Souza; e que resistiram até o tempo que o Arcebispo Dom José Gaspar, à sombra delas, lia o breviário, enquanto crianças, que hoje são velhos, saltavam o muro para roubar pitangas no jardim do arcebispo."1

Depois da queda do Império, toda a família retraiu-se da vida pública, concentrandose aos poucos na chácara, levantando suas residências dentro de seus limites, nos dois lados da rua de São Luiz. Assim a família inteira morava na mesma rua.

Como se pode perfeitamente notar, o processo de loteamento da chácara neste caso, foi especial, visto que ela foi simplesmente "dividida" em lotes, sem um fim lucrativo, como ocorreu em outros processos de loteamentos de chácaras na cidade de São Paulo.

Aocontrário do que ocorrera no período de 1828 a 1872, quando em linhas gerais a casa paulistana se mantivera fiel aos moldes tradicionais que vinham da era colonial; no período seguinte, de 1872 a 1918, a transformação foi bastante pronunciada, rompendo-se de forma radical com tudo que a experiência havia ensinado aos velhos mestres de obra paulistanos.

Isso ocorreu por imposição de circunstâncias que se originaram com o próprio crescimento rápido da cidade, em consequiência do enriquecimento de novas zonas da província com o surto do café e as primeiras ligações ferroviárias. Entre os novos moradores, encontravam-se vários fazendeiros abastados, que puderam, com a colabo- 
ração de arquitetos e empreiteiros italianos e de outras nacionalidades, edificar palacetes, vilase chaléscujas linhas estabeleciam um vivocontrastecom as velhas casas acaçapadas de tradição portuguesa.

O último quartel do séc. XIX, assim como os primeiros anos do séc. XX, representou um período de muita demolição, reforma e construção na cidade e seus arredores.

As residências particulares formavam rapidamente bairros novos, e se estenderam em todas as direções, ostentando luxo e conforto notáveis, embora tivessem por vezes uma estética bizarra e um tanto duvidosa.

A virada do século vem encontrar esta rua, a rua de São Luiz, de 300 metros apenas, ladeada de palacetes ecléticos, condizentes com a arquitetura vigente no final do séc. XIX, todos pertencentes a um só clã.

O período que vai do início do século até aproximadamente 1930/40, apresenta praticamente nenhuma alteração na configuração espacial da rua de São Luiz, apesar de que o Circolo Italiano já se instalara num dos palacetes (onde está hoje o edifício Itália), e outro (o que se situava no que seria mais tarde os fundos da biblioteca), era Palácio Episcopal desde 1909; e alguns foram adquiridos por outras famílias, perdendo assim seu caráter de clã, mas a paisagem apresentava ainda uma certa homogeneidade, um contínuo de palacetes edificados nas mais diversas tendências do ecletismo paulistano.

Segundo Yan de Almeida Prado: "Referimo-nos à rua de São Luiz. Vista à tarde é uma maravilha. A arborização de cajazeiros forma um túnel verde, que se junta as outras árvores, algumas seculares, dos jardins próximos. A rua não é longa, em compensação, está ladeada de palacetes, outrora pertencentes à família Souza Queiróz. Temos, logo no começo, ainda na praça da República, a velha casa de Augusto de Souza Queiroz, onde no governo do Sr. Campos Salles conspirou-se contra o regime. Um dos conspiradores era Eduardo Prado. Ao lado, na esquina da rua São Luiz, o palacete de Luiz Antonio de Souza Queiroz, depois vendido a um comerciante português. $O$ palacete fronteiro também pertencia à mesma família, e hoje está de posse do Circolo Italiano. De todos era o mais grandioso e interessante. Na continuação da rua persiste a continuação dos Souza Queiroz. Porém essas vivendas já pertencem a outro gênero, foram construídas sob influência italiana. Os doispalacetes SouzaQueiroz,construídos, na outra extremidade, nas duas esquinas das ruas da Consolação e São Luiz, enquadram-se nesse gênero. Igualmente, o do Sr. Carlos de Souza Queiroz, onde hoje está a residência do arcebispo. Todos eles apalaçados, no meio de grandes parques e velho arvoredo"?. 


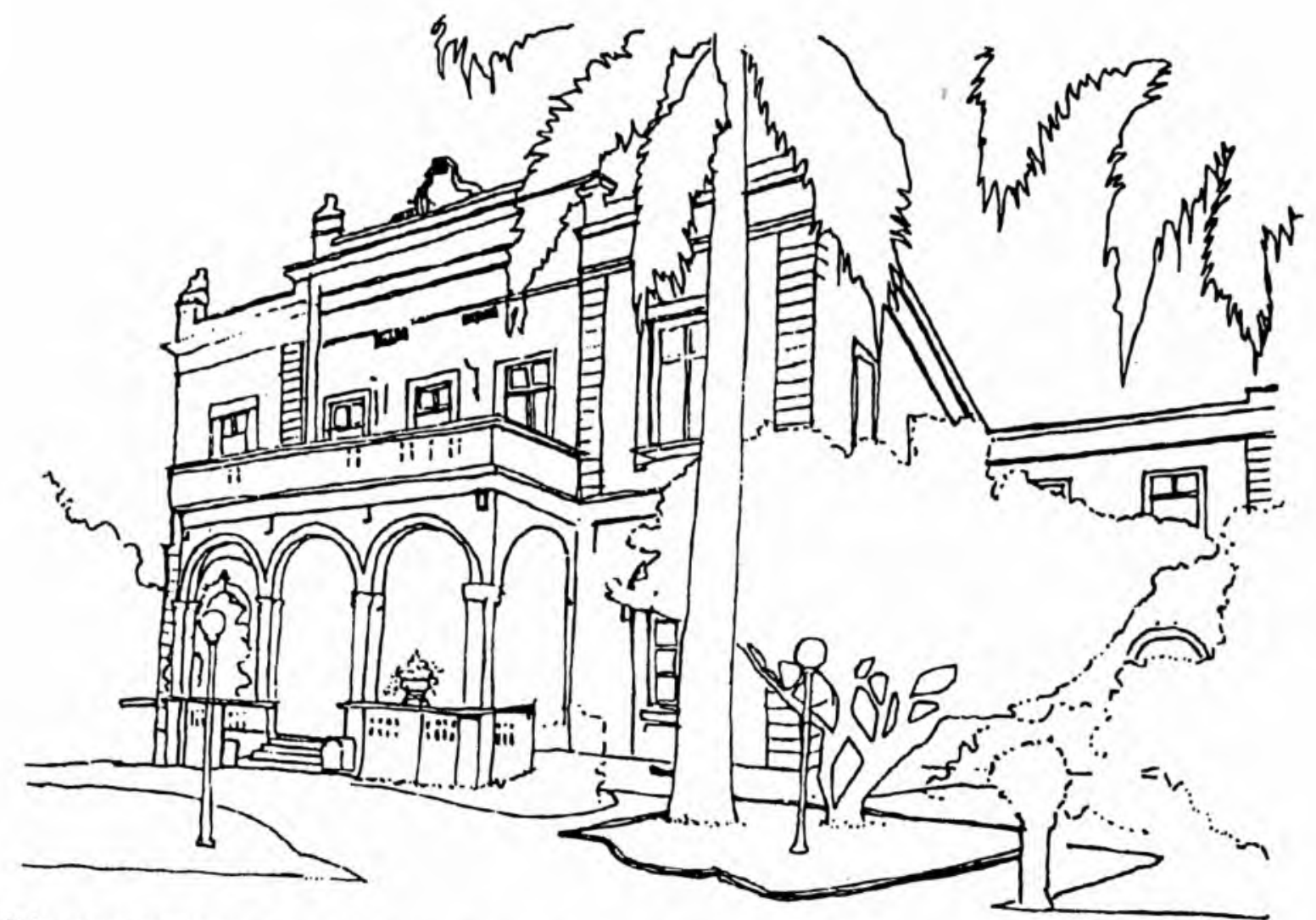
Palacete construído por Francisco de Souza Queinóz na virada do século sendo adquirido pelo Circolo Italiano em 1927, e
demolido para dar lugar ao Edifício Itália, na esquina das avenidas São Luiz e Ipiranga.

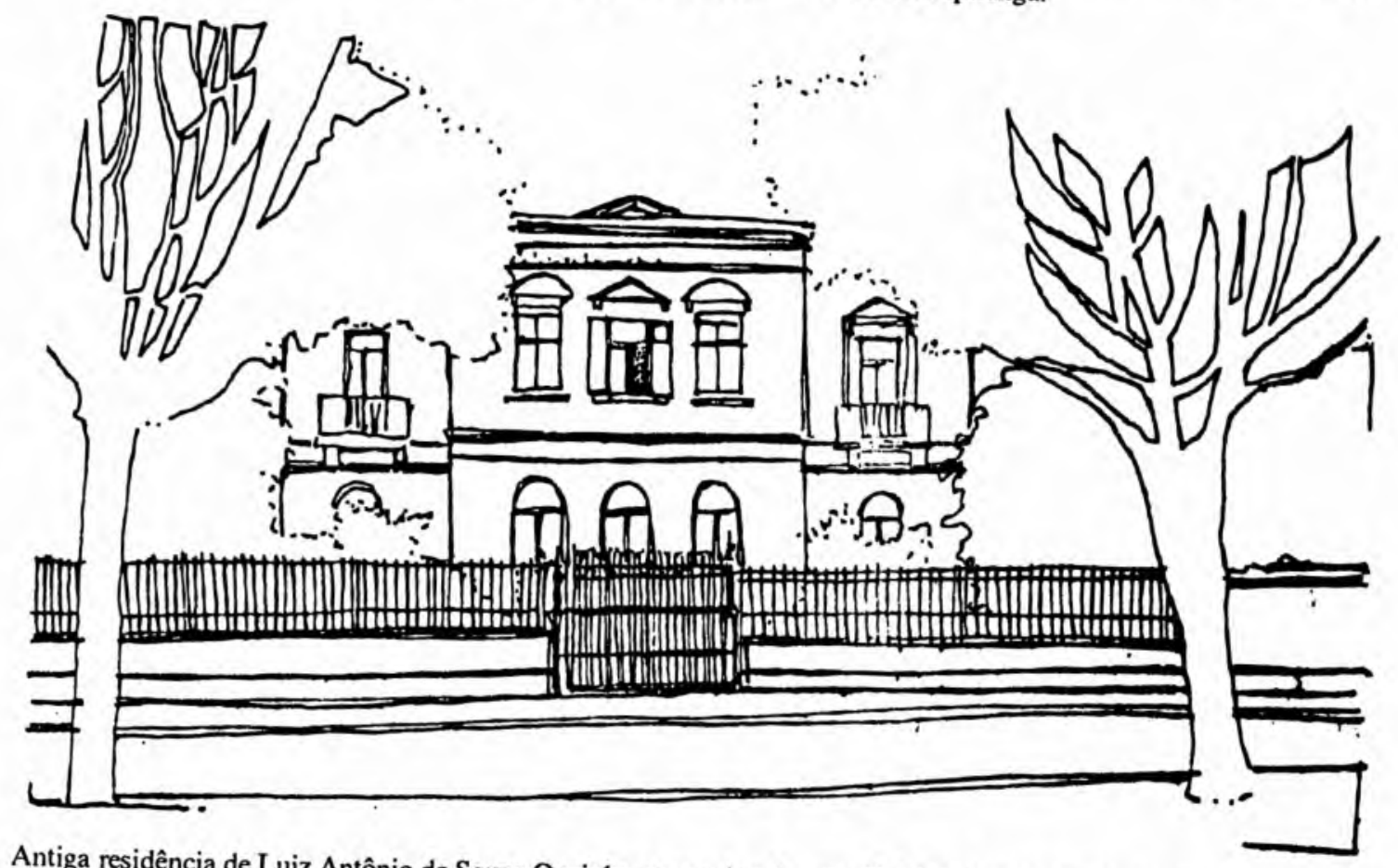
Luiz. 


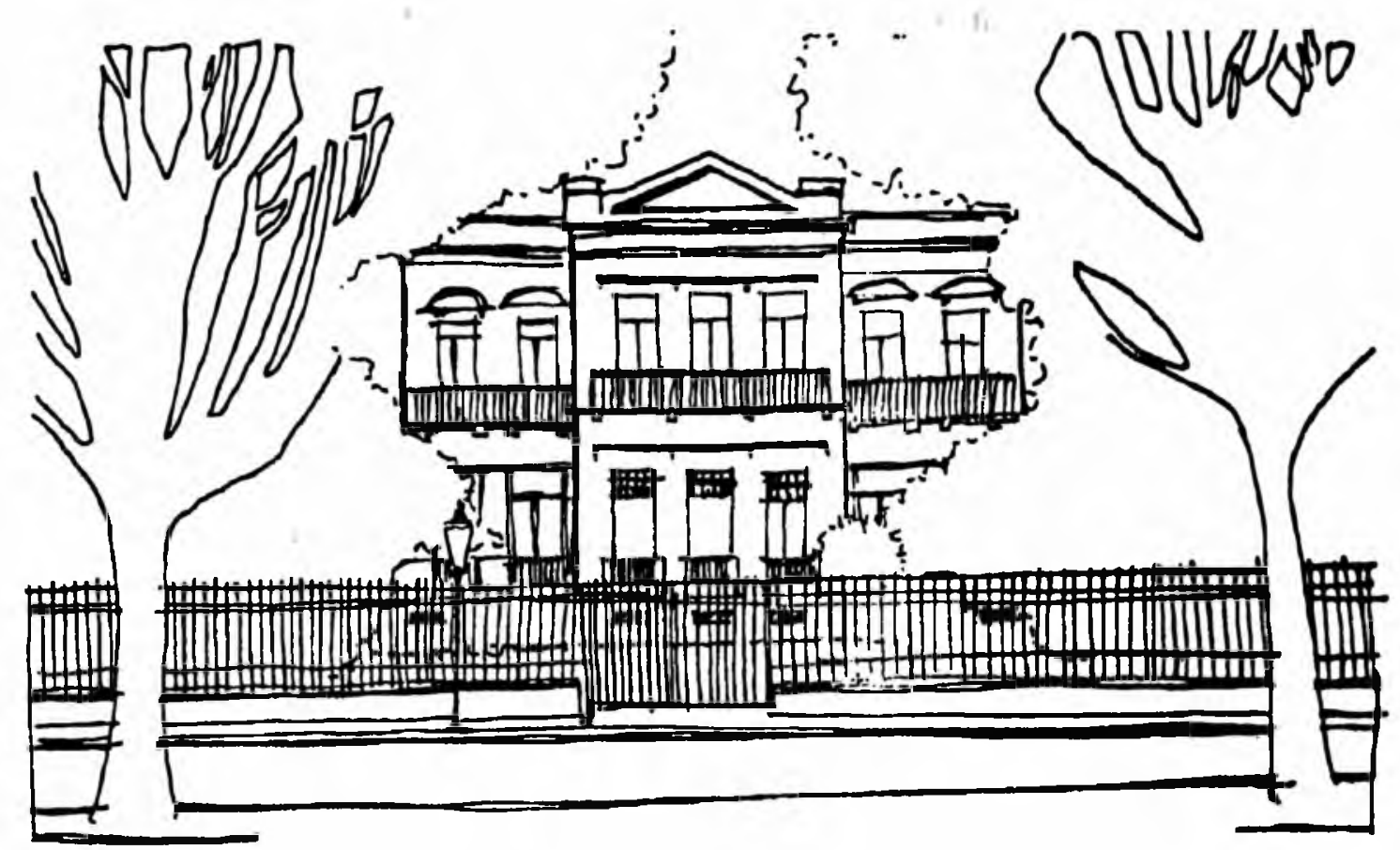

Antiga residência de Augusto de Souza Queiróz, na esquina das mas Epitácio Pessoa (atual avenida Ipiranga) e Sete de Abril, onde hoje está o Edifício Esther.

\section{$1930-1972$}

A expansão do "centro"paraalém da colina históricaprocessou-se muito vagarosamente. O viaduto do Chá, existente desde 1892, pouco contribuiu para esta expansão nas três primeiras décadas do séc. XX. Antes e depois de sua construção, a área compreendida entre o Anhangabaú e a praça da República, era tipicamente residencial, como já foi dito. Esta, embora tão perto, constituía-se, nesta época, no trecho inicial da "cidade nova", em contraposição ao velho núcleo. Foi somente a partir da década de 40 que teve lugar a integração dessa área ao centro.

Até o final da década de 50 os usos e a configuração espacial alteraram-se de maneira bastante significativa na avenida São Luiz. Transformou-se a rua de São Luiz em avenida São Luiz, sendo alargada por Prestes Maia para fazer parte do Perímetro de Irradiação em seu "Plano de Avenidas para a Cidade de São Paulo"; fazendo com que os palacetes do lado ímpar da rua perdessem seus jardins, e alguns fossem até demolidos para o alargamento da via. A ultrapassagem do comércio e prestação de serviços do Triângulo Central para o que era então denominado "Centro Novo", ou seja, a área que vai da rua Barão de Itapetininga até as imediações do viaduto do Chá, visto que esta estava mais próxima dos bairros de elite; contribuíram para tal transformação, alterando consideravelmente sua paisagem. 
Transformada em avenida, a São Luiz continuou evoluindo. Os casarões foram sendo derrubados um a um, e substituídos por grandes edifícios, os primeiros prédios de apartamentos de alto luxo que aparecem na cidade, alguns inclusive significativos enquanto exemplos da "implantação" definitiva da arquitetura moderna em São Paulo, em contraposição ao ecletismo, que vigorou até a década de 30/40 aproximadamente.

Esta época foi o tempo da propagação do concreto armado, e também quando se aceita definitivamente oprédio de apartamentos como solução de moradia, atéentão rejeitado, especialmente pela classe média, que comparava-o aos cortiços das classes baixas.

Para a arquitetura brasileira, a década de 30 foi um período de manifestações isoladas do modernismo, mas sem muita repercussão, interessando somente a um ou outro curioso. Somente no final da década de 40 o quadro da arquitetura paulista começa a alterar-se, tendendo a um pensamento coletivo voltado para a modernidade, devido basicamente a dois fatos: a chegada de um significativo número de arquitetos estrangeiros, na sua grande maioria refugiados de guerra, dotados de grande valor profissional; e a instalação da Faculdade de Arquitetura, a do Instituto, hoje Universidade Mackenzie, e da Universidade de São Paulo.

\section{$1972-19 \ldots$}

Assim, num segundo momento, até a década de 70 aproximadamente, o uso residencial na avenida São Luiz convive funcionais, como comércio e prestação de serviços por exemplo, típicas de área central, mas ainda com uma predominância da paisagem residencial, só que não mais de palacetes e chalés envoltos em caprichosos jardins, e sim de grandes e luxuosos edifícios de apartamentos.

Depois da demolição do último palacete na avenida, em 1972, se consolidou uma paisagem de área central, que domina a região atualmente, mas com características bastanteespecíficase peculiares, visto queelaé a única avenida ou rua do "Centro Novo" onde se verifica um certo equilíbrio entre as funções típicas do centro e a função residencial, facilmente explicado pelo fato que quase todos seus edifícios são de uso misto, isto é, os andares superiores geralmente são apartamentos, enquanto os dois ou três primeiros são lojas, restaurantes, bancos, agências de turismo, etc.

Mas não só a mudança de usos e a "substituição" dos palacetes por edifícios e o alargamento da via que contribuíram para a mutação da paisagem na avenida São Luiz. No início da década de 70, os jacarandás, condenados por pragas, foram substituídos por tipuanas, até que em 1978 as obras da estação República do metrô destruíram os 250 metros do canteiro central, a pretexto de evitar futuros congestionamentos na área. 
Mas apesar dos protestos e pedidos dos moradores, somente com a conclusão das obras em 1982 é que o canteiro central da São Luiz foi novamente reconstituido, dando-lhe a configuração que vemos hoje em dia.

Atualmente, durante a semana, o tráfego de veículos e pessoas é intenso, que trabalham na própria avenida ou procuram ali seus serviços. Já no final de semana, não há praticamente nenhum movimento. Também é interessante notar, que o mesmo se verifica na praça Dom José Gaspar, ao lado da biblioteca. Apesar da praça se localizar numa rua onde a maioria dos edifícios são de uso residencial, mas sem possuírem áreas de lazer próprias (característica comum aos primeiros prédios de apartamentos), esta não é utilizada para tal finalidade. Já durante a semana, de modo geral a praça serve mais como um caminho, uma "passagem" para se atingir o "Centro Novo", ou então na hora do almoço, pelas pessoas que freqüentam os restaurantes e lanchonetes da Galeria Metrópole e proximidades.

\section{NOTAS}

(1) O Estado de S. Paulo. 29/junho/1971.

(2) PRADO, Yan de Almeida. São Paulo Antigo e sua Arquitetura. Revista llustraçāo Brasileira, 1929. 


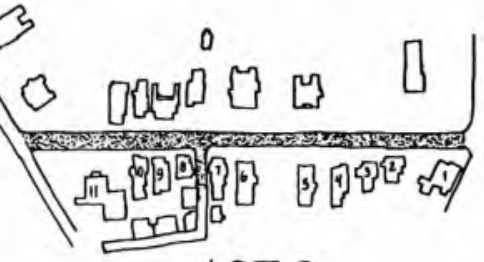

$1930_{\text {bhpox }}$

ESC. 1500

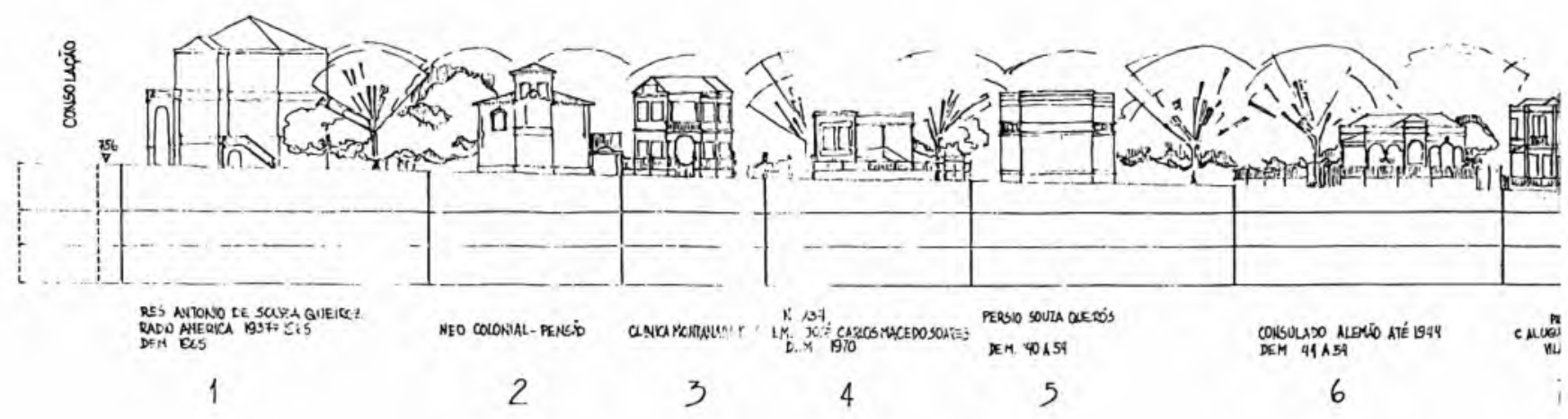

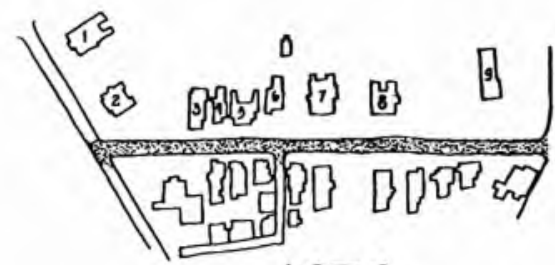

1930 lado mper

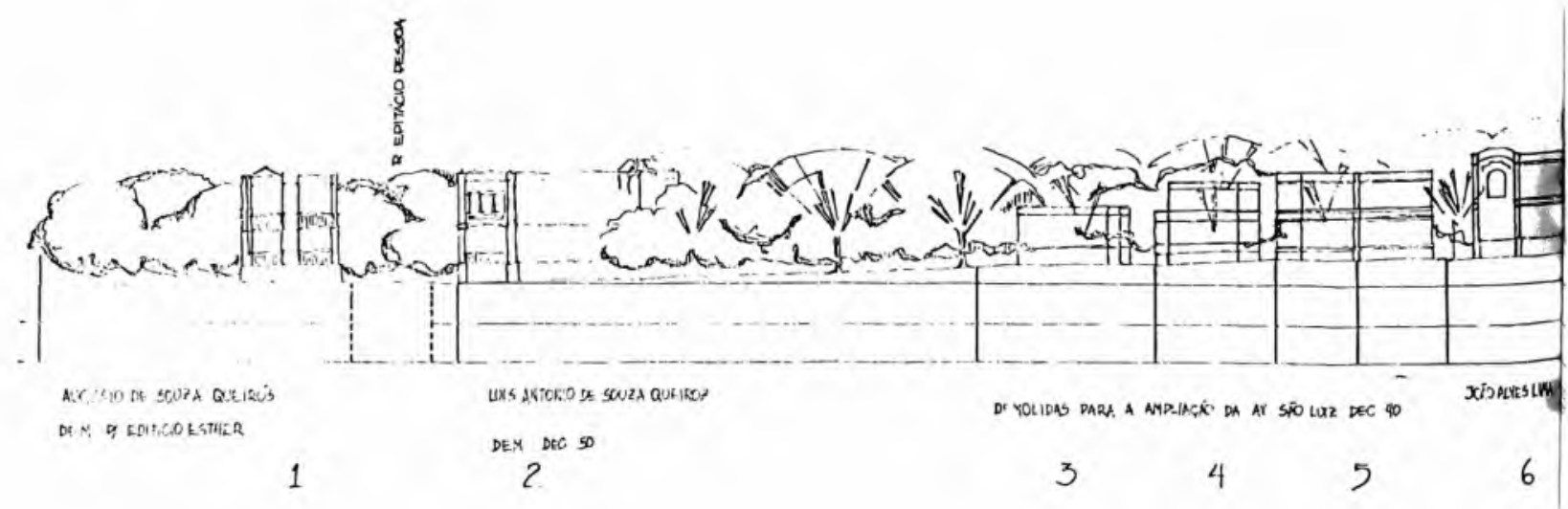




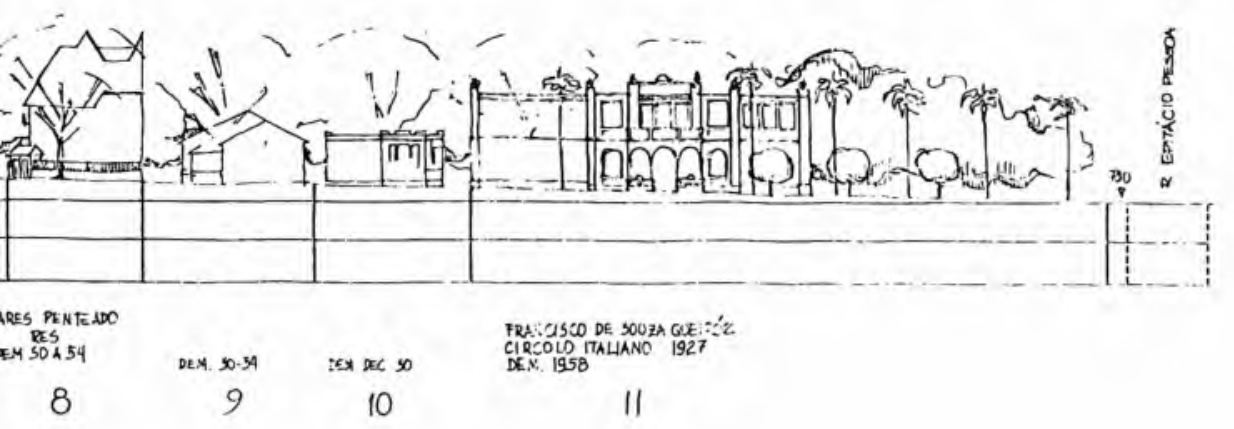

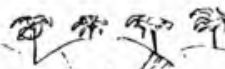

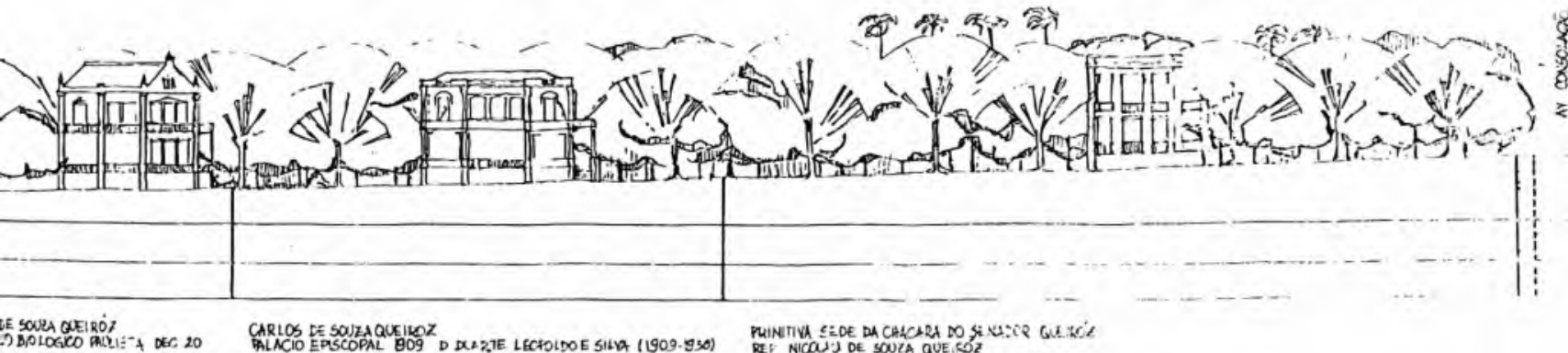

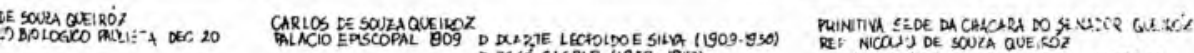

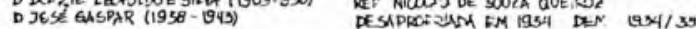




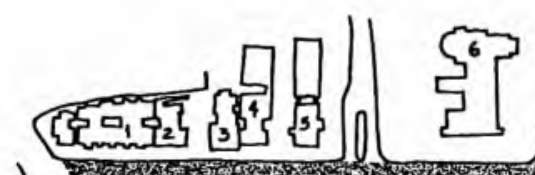

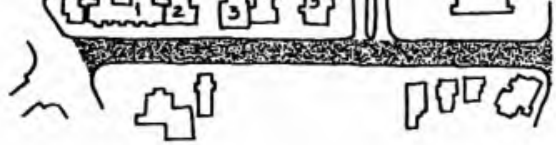

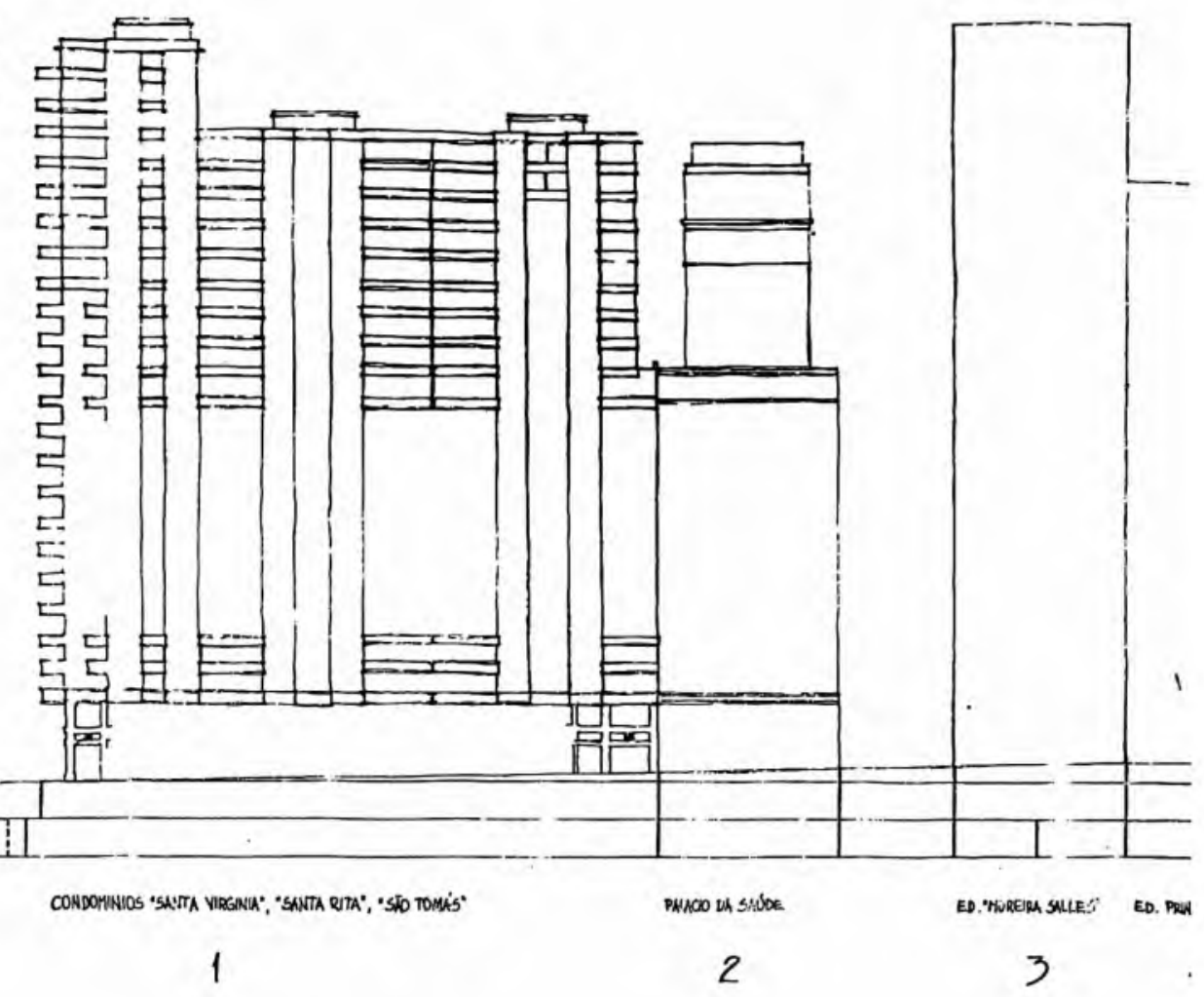

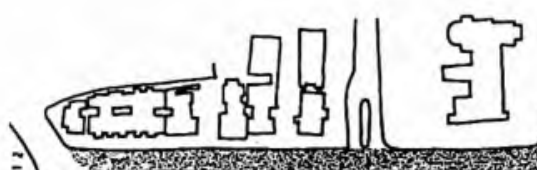

$3)^{3}$ एव

1954 bo of

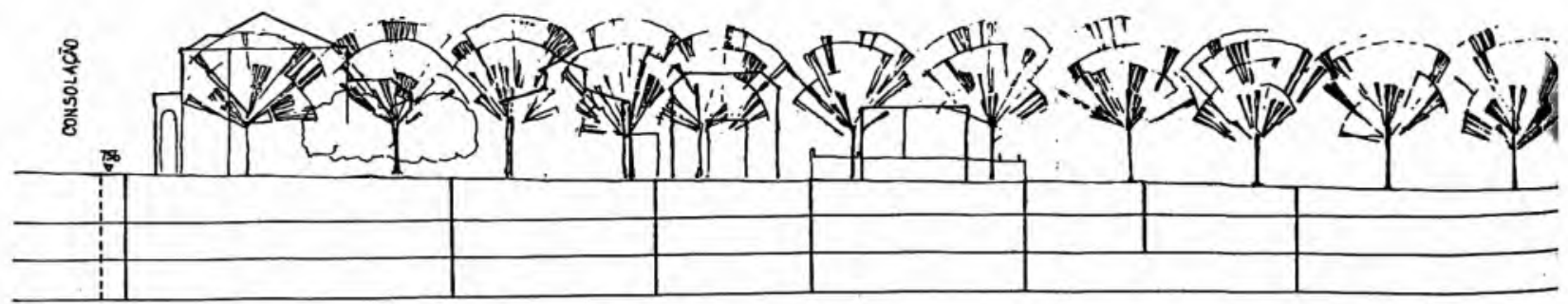

5E) $40 \mathrm{A54}$ 

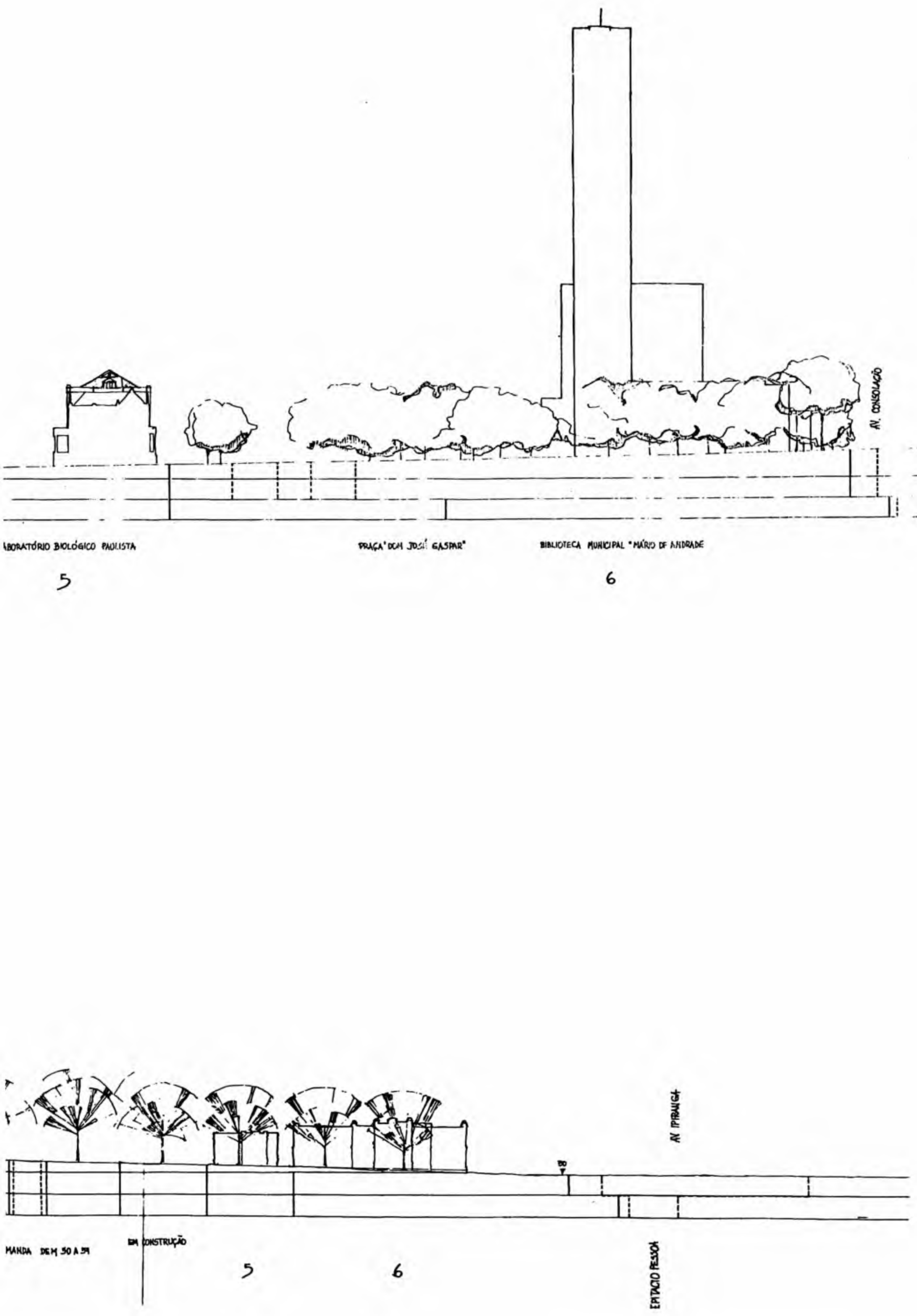